\title{
THE EVALUATION OF THE INFLUENCE OF TECTONIC STRUCTURE OF NIKOLAYEVSKY DEPOSIT ON ROCK-BURST HAZARD OF ROCK MASS
}

\author{
Aleksandr Sidliar ${ }^{1}$, Boris Saksin $^{1}$, Pavel Anikin ${ }^{1}$ and Mikhail Lomov ${ }^{1}$ \\ ${ }^{1}$ Institute of Mining of Far Eastern Branch of the Russian Academy of Sciences, Khabarovsk, Russia
}

\begin{abstract}
Using the joint analysis of seismoacoustic monitoring data and geodynamic features we have determined the consistent patterns of industrial stress field formation in deep aquifers of Nikolayevsky polymetallic deposit. This analysis allowed us to explain the hypothesis about the mechanism of hazardous geodynamic phenomena in the complex structure rock mass. Results of the research on the geostructural features of the Nikolayevsky scarn-polymetallic deposit allowed us to improve its geodynamic zoning. As the result, we have discovered major heterogeneity of the geological environment of the ore field, which defines its modern structure, as well as features of the strain-stress state of the rock mass (olistolith).
\end{abstract}

\section{Introduction}

The problem of rock-bump hazard in the underground mines of Far Eastern region has been relevant for decades. Rock pressure, which is inevitable during underground exploitation of deep aquifers, and high tectonic stress level of the rock mass pose a great threat to worker's lives, interfere with the normal work process during mining operations, thus reducing efficiency of mining production [1, 2]. Solution to the problem of rock pressure management is yet to be discovered, because of, to a large extent, insufficient study of the nature and mechanisms of geodynamic processes and phenomena appearing in the rock mass under the influence of multiple natural and industrial factors.

One of the most hazardous deposits in the Far East is Nikolayevsky polymetallic deposit, located in the East Primorye. It is characterized by its complex geological structure and confinedness to the tectonically active regions of the crust [3].

Monitoring the deposit between 2011 and 2018 registered more than 250 dynamic occurrences of rock pressure in various forms: from pressure burst to rock and rock-tectonic bumps. Thanks to continuous employment of geomechanical monitoring and timely taken stress-relief actions at the Nikolayevsky deposit, the amount of dynamic occurrences in the

\footnotetext{
${ }^{1}$ Corresponding author: alex-igd@mail.ru
} 


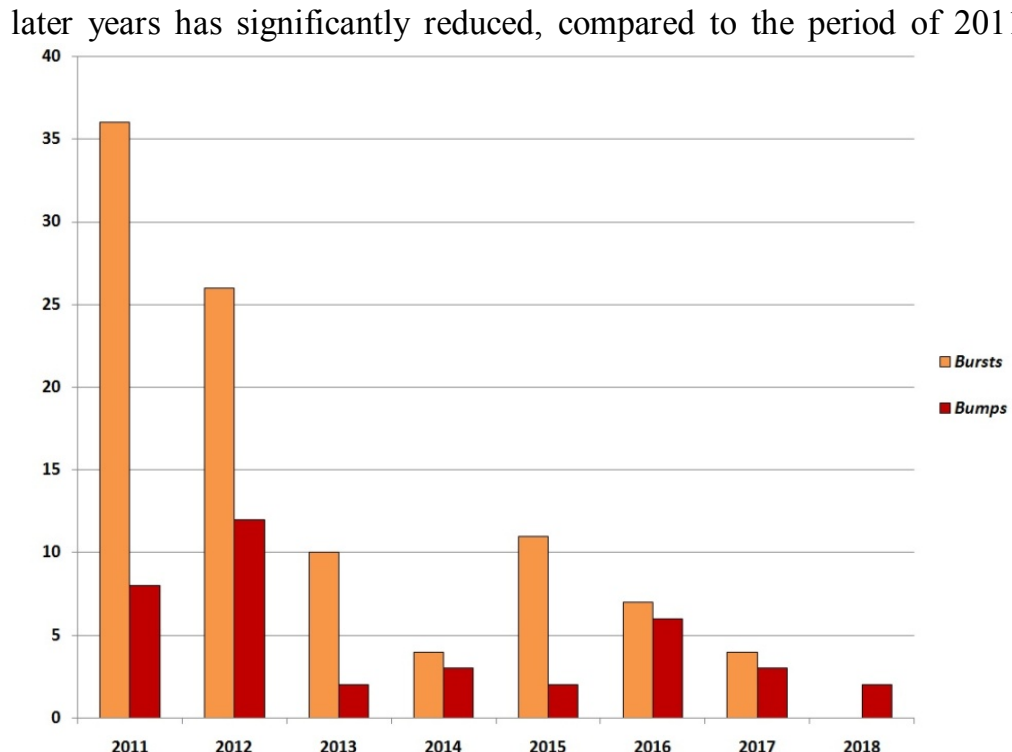

Fig. 1. Distribution of dynamic occurrences of rock pressure (bursts and bumps) at the Nikolayevsky deposit, 2011-2018.

\section{Analysis of seismoacoustic monitoring results}

Unlike other deposits in the Far East, evaluation and rock-bump hazard control at the Nikolayevsky deposit is conducted by instrumental measurements of seismoacoustic activity of the rock mass with the help of digital geoacoustic monitoring system "PrognozADS" and local control tool "Prognoz-L", as well as systematic visual monitoring of dynamic occurrences of rock pressure in the mines.

"Prognoz-ADS", automated rock pressure control system, which is used to estimate rock-bump hazard level in the region, provides effective collection of acoustic signals, their digitization, processing and transmission by digital communication lines to the central computer, which controls the measuring and computing system $[4,5]$.

Currently, the monitoring network includes 21 digital receiving transducers (DRT) mounted in the wells within the mines on aquifers $-323,-360,-380,-390,-406,-420,-433$.

In total, the geoacoustic monitoring system "Prognoz-ADS" has registered more than $17,000 \mathrm{AE}$ events between 2011 and 2018. Retrospective analysis of the results of seismoacoustic monitoring, conducted from 2011 to 2018 , showed that most of them were limited to mining sites, as well as fault network, especially the active subvertical fault TN3 (fig. 2). Sites of the mine field at the southern and north-western flanks of the deposit show the most seismoacoustic activity. 


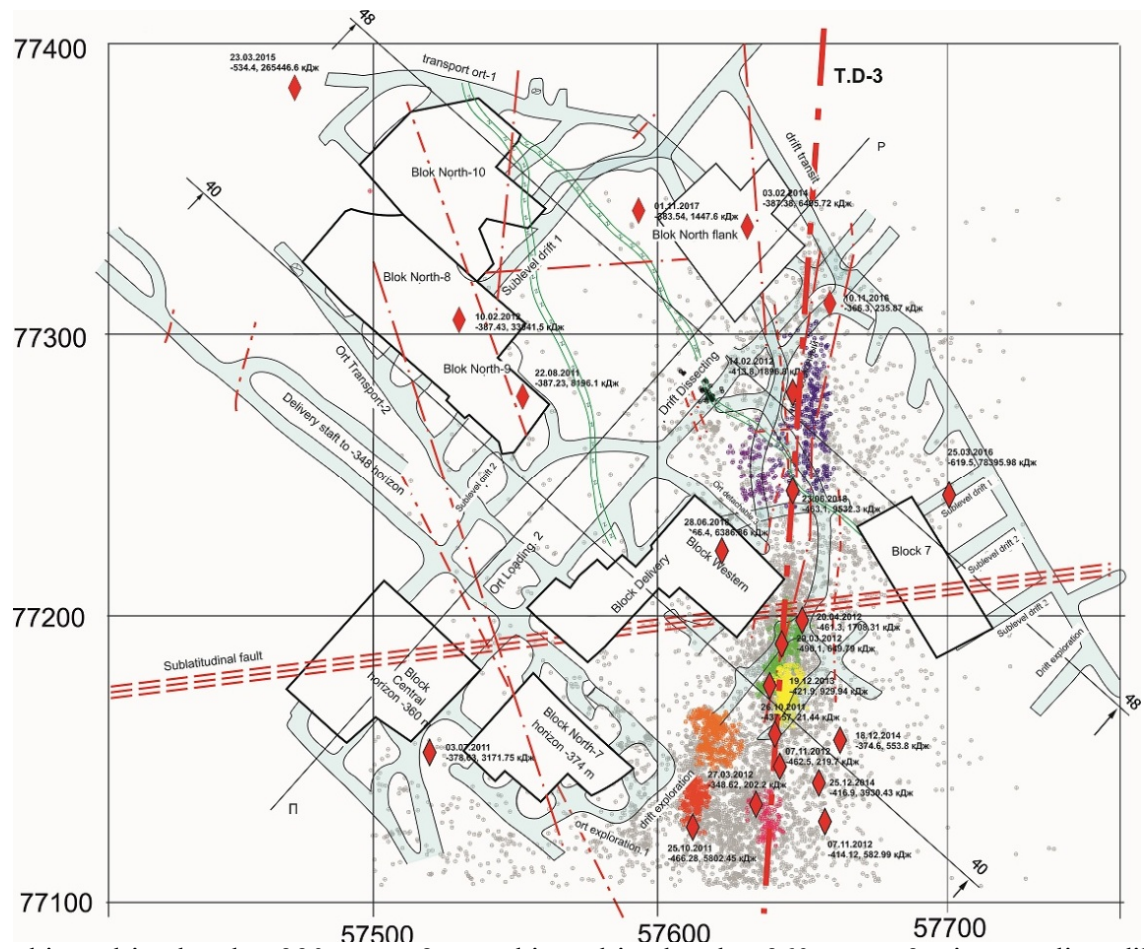

1 - workings drived at the $-390 \mathrm{~m}$ aq.; 2 - workings drived at the $-360 \mathrm{~m}$ aq.; 3 -intermediate dike; 4 - stripped space of the stope a) at the $-390 \mathrm{~m}$ aq.; b) at the $-360 \mathrm{~m}$ aq.; 5 - blocking sub-lateral fault; 6 - tectonic disturbances a) of the second order; b) other; color shows source zones

Fig. 2. Map of acoustic activity of the Nikolayevsky deposit mass according to seismoacoustic control data in 2011-2018.

Analysis of major dynamic occurrences reveals the similar picture. Between 2011 and 2018 Prognoz-ADS system registered 29 shocks at the deposit. Majority of them was limited to the fault network, especially to the active subvertical submeridional fault TN3 with the accompanying fracture set, specifically at the sites of its interception with subvertical dike bodies of diabase porphyrites, predominantly in the north-west direction (fig. 2). This structure represents the area of increased fracture density up to 50-60 m wide, with scattered sulphide mineralization and separate crushing zones.

It is worth mentioning that most of the shocks registered within the tectonically active TN3 fault initiated as the result of seismic influence, both natural and industrial (after blasting works).

For example, a strong geodynamic event was registered on March 25, 2016, at 12:57 AM near the Vostok-1 ore deposit (block 40). It was accompanied by the powerful acoustic occurrence, shaking of the whole mine field and seismic vibrations recorded in the overground mining complex. As the result of this event, the lining and walls of the mine at the aquifers $-375,-390,-406,-420 \mathrm{~m}$ were damaged. The volume of destroyed rock mass inrush exceeded $400 \mathrm{~m}^{3}$. During the first hours after the geodynamic event, acoustic activity of the rock mass more than two times exceeded the average level. As noted earlier [6, 7], the time of the described event matched the time of the earthquake of the 4th magnitude in Kamenka village at the Japanese sea coast. The described geodynamic event resulted in the appearance of open faults and fractures dozens of meters long in the rock mass. There were cases of soil elevation for 10-12 cm along the fault borders, and faults themselves coincide with elements of deposit tectonic structure (fig. 5). 
Therefore, at the Nikolayevsky polymetallic deposit, which had the most of hazardous geodynamic events in the recent years, we revealed the pattern for nature-industrial stress field formation, resulting to a large extent from rock mass tectonic structure and complex geometry of the mined-out area. The majority of registered AE events and major dynamic occurrences (shocks) is limited to the fault network, especially to the area of the active subvertical fault T3 with accompanying fracture sets, subvertical dike bodies, predominantly in the north-west direction. Analysis of experimental data allowed us to explain the hypothesis about the mechanism of hazardous geodynamic phenomena in the complex structure rock mass, according to which these events are limited to the areas in boundary state of stress at the borders of tectonic blocks and initiate as the result of a natural or industrial seismic influence.

\section{Geodynamic features of the deposit}

We contrasted geomechanical monitoring data with the features of Nikolayevsky deposit tectonic structure, where the large complex limestone slab (olistolith) plays a major role. In the area of study we registered zones of abnormal increased seismoacoustic activity of two types: areal (near-isometric) and more local (elongated) (fig. 3).

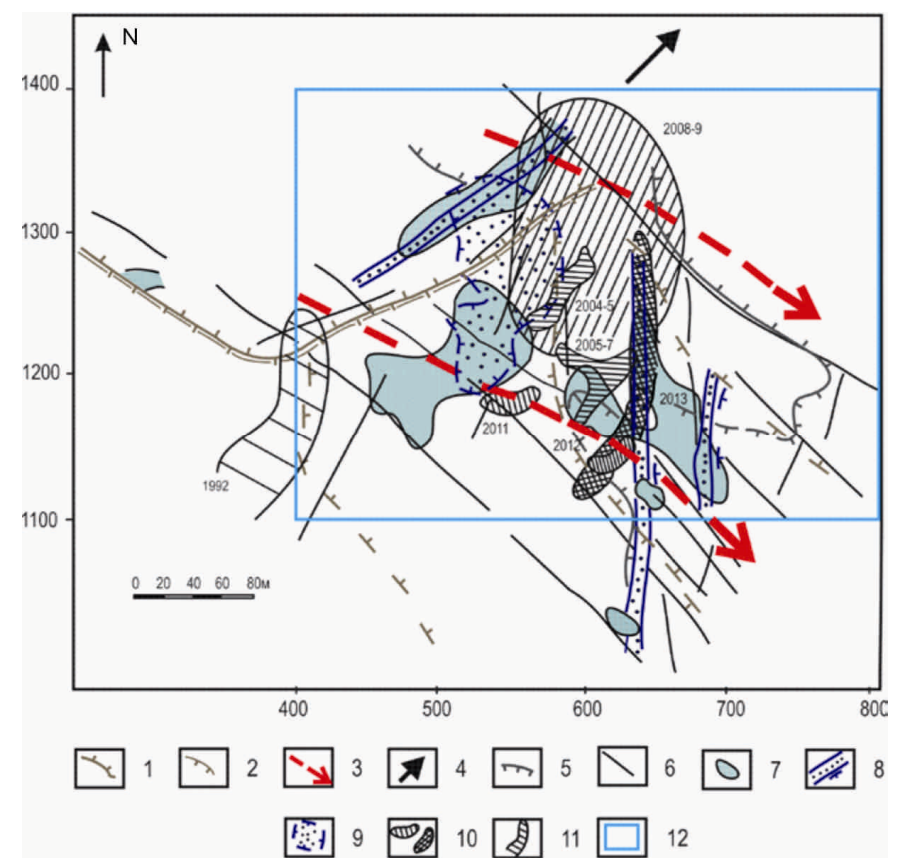

1-2 - axial water-parting lines in limestone back geometry (ridge-like olistolith offsets): 1 - primary, 2 - secondary; 3 - direction of ore body subsidence; 4 - direction of modern horizontal movement of ore hosting geoblock and main horizontal rock mass compression at the aquifer $-320 \mathrm{~m} ; 5$ - area of sharp drop of absolute marks of limestone olistolith back; 6 - back geometry lineaments (conjectural neotectonic faults); 7-8 - sites of lower metasomatite increased capacity: 7 - isometric; 8 - linear (chasms in limestone bodies filled by metasomatites) and direction of their fall; 9 - location of the lower rim of resurgent feeder for upper metasomatites; 10 - results of acoustic monitoring between 2004 and 2013 (different hatching shows anomalies discovered in the specified years); 11 - region of rock pressure dynamic occurrence registered in 1992; 12 - outline of geoacoustic monitoring

Fig. 3. Interpretation results of the maps showing modern morphology of large limestone slab back, as well as lower metasomatite bodies in the Nikolayevsky deposit 
We began to analyze the data by constructing summary olistolith block graph (fig. 4), where we put our predecessors' views $[8,9]$ on block boundaries, which were based on geological data, and our suggested geodynamical zoning of the studied part of the object (at the modern stage of development), based on different morphological expressiveness of regions with uneven modern geodynamic condition.

Moreover, the figure shows lithological irregularities which, as monitoring process showed, influence the distribution of seismoacoustic abnormalities.

Morphology of olistolith outline on the graph leads to a conclusion that it is defined by faults of the following directions (starting from the most important): submeridional, northwest, and north-east. This is confirmed by the results of geological prospecting work, according to which the olistolith body is split by a series of faults that are a part of the main meridional structure of the ore field, secant in relation to faults in other directions. Three blocks of the first order are formed by the intersection of sub-lateral fault and north-western tectonic zone (see fig. 4). They are split into smaller blocks by faults in other directions. Most of the faults are subvertical. Comparison of fig. 3 and 4 shows that there is no distinct connection between the abnormal zones discovered by monitoring and blocks of the I order. We can only note the confinedness of lateral-oriented abnormal zones to sub-lateral fault separating Central and Northern blocks. At times seismoacoustic anomaly is controlled by the faults of another rank (for example, TN3 and other smaller faults in north-west direction), which are most likely limiting blocks of a higher order (not shown on the graph).

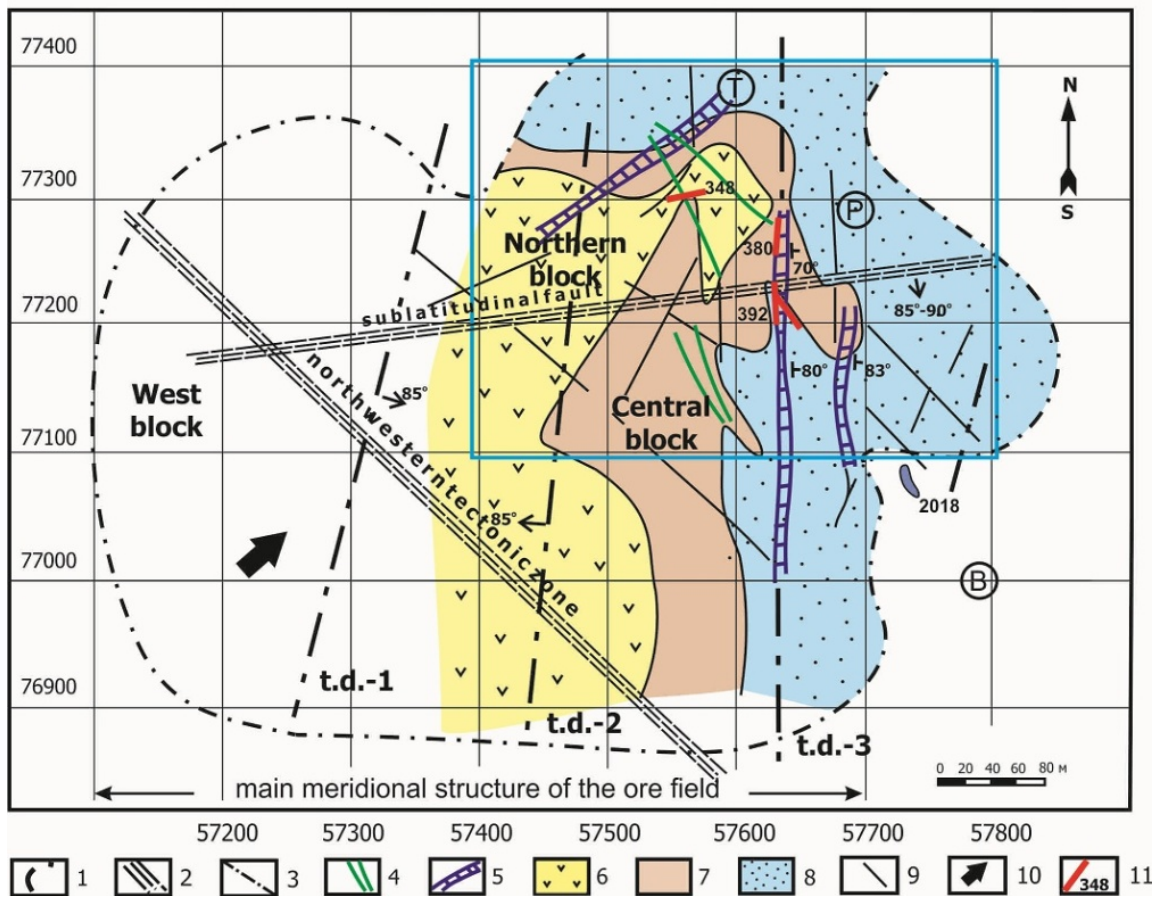

1 - projection of olistolith outline to a horizontal plane; 2 - block-forming faults and their names; 3 other tectonic disturbances and their numbers; 4 - dikes of average and main composition; 5 - chasms in limestone bodies filled by metasomatites; $6-8$ - geodynamical regions formed by olistolith morphological features and modern stress field: 6 - relatively stable geodynamic region; 7 - slightly sloping region with intermediate geodynamic activity; 8 - steep lateral geodynamically active region; 9 - olistolith back geometry lineaments; 10 - direction of the main horizontal rock mass compression; 11 - location of fractures and cracks created by the earthquake on 03.25.2016.

Fig. 4. Ore hosting limestone olistolith body block structure of the Nikolayevsky deposit and its modern geodynamic zoning 
Consistent patterns of interaction between natural and industrial systems can be indicated more distinctly by the joint analysis of results of local monitoring and complex research aimed at discovering currently active block-tectonic forms. As you can see on fig. 4 , location of abnormal areas is controlled by the intersection of primary and secondary ridge-like olistolith body offsets. Within the studied area the main water-parting line is of north-west direction, along the modern horizontal compression, and the secondary ones are oriented perpendicular to it. The largest areal anomaly, discovered in 2008-2009, is located at the commissure of the main water-parting line with two secondary ones, and also at the joint of divergent zones, where the absolute marks of olistolith back drop sharply, and where the vertical channel for upper metasomatites is fixed. Therefore, areal anomalies conceal the most stressed areas of a relatively stable geodynamic olistolith region.

In the south-west direction from the main water-parting line we first encounter local anomalies mainly of north-east, less often north-west and sub-lateral orientation that are likely to be limited to the crevasses in olistolith body, which appear under the influence of mining works along the direction of primary and secondary water-parting line orientations. Incidence rate of linear local anomalies increases in the regions with intermediate geodynamical activity and in active lateral ones. The latter ones are characterized by occurrence of elongated linear local anomalies limited to fault zones in meridional direction. These crevasses in olistolith body are formed during premineral and mineral stages of the geological development of the region, because they are cured by subvertical bodies of wallrock metasomatites. These crevasses are distinguished by the fact that acoustic emmission anomalies in them are registered even at significant depths. The lateral olistolith region, currenlty geodynamically active, is also characterized by the presence of chasms in its back geography, cured wallrock metasomatites and increasing degree of its absolute mark drop. All of the above indicates the increased small-block nature of olistolith body structure towards the lateral area (subvertical eastern olistolith rim), which determines increased rock-bump hazard in the south-west direction occurring downward the mine.

Therefore, geodynamics of the territory of the region results from confinedness to the concealed deep submeridional fault, shifts in which defined the elements of the tectonic structure of the deposit. It is characterized by its block composition, main elements of which are subvertical sub-lateral fault and north-west tectonic zone, breaking the ore field into three main structural blocks: central, northern and western. Within the boundaries of the deposit we can also see elongated subvertical ruptural post-mineral disturbances in the submeridional direction (fig. 4) [10].

Under these conditions we need more thorough and complex geodynamic research, including the following: identifying the consistent patterns of current strain-stress state formation of the rock mass and evaluation of geodynamical and seismic conditions based on it, as well as the strain-stress state of the rock mass; investigating the role of natural and industrial influence in conjunction with strain-stress state of the rock mass in order to lay the basis for measures for managing rock pressure and decreasing geodynamic risks.

\section{Conclusions}

1. We revealed the features of acoustic activity occurrence in the rock mass of Nikolayevsky deposit at the stage of formation of potentially rock-bump hazardous zones. The majority of the registered AE events was limited to the fault network, especially to the active subvertical submeridional fault TN3 with the accompanying fracture set, specifically at the sites of its interception with subvertical dike bodies, predominantly in the north-west direction. We revealed the correlation between the dynamic occurrences of rock pressure and seismic waves from natural (earthquake) and industrial (technological blasts) sources. 
Seismic waves act as a trigger and initiate destruction in the dynamic form of rock mass sites in boundary state of stress.

2. After studying the conditions and reasons for minihg tectonic impact on March 25, 2016, at the Nikolayevsky polymetallic deposit, which caused sizeable damage to the mines at various aquifers, appearance of faults and fractures dozens of meters long with cases of soil elevation for 10-12 cm, we established that dynamic occurrences of rock pressure and industrial seismicity at the deposit is determined, to a large extent, by complex geodynamic processes in form of realignment and self-organizing of the mass in nature-industrial stress field, which are accompanied by various displacement along the tectonic disturbances of different scale.

3. The main irregularity of the geological environment of the ore field, which defines its modern structure and features of strain-stress state of the rock mass, is a large inclined stratified limestone slab (olistolith). Any displacement in this rigid slab results in activation of previously formed structures, and morphology of its back highlights the occurring movement and determines strain-stress state of various parts of the plate. The results of studying geostructural features of Nikolayevsky scarn-polymetallic deposit helped us specify the graph of its geodynamic zoning, including the construction of summary limestone olistolith block graph, which allows us to give more reliable interpretation to seismoacoustic monitoring data highlighting the geomechanical processes in the exploited rock mass and determine potentially rock-blast hazardous areas.

\section{References}

1. M. Henryk, G.Z. Mutke. Journal of Seismology. 17(4). 1139-1148. (2013).

2. P.E. Snelling, L. Godin, S.D. McKinnon. International Journal of Rock Mechanics and Mining Sciences. 58. 166-179. (2013).

3. I.Iu. Rasskazov, B.G. Saksin, V.A. Petrov, B.F. Shevchenko, V.I. Usikov, G.Z. Gil'manova. Izvestiya, Physics of the Solid Earth. 50 (3). 444-452. (2014).

4. I.Iu. Rasskazov, M.I. Potapchuk, G.A. Kursakin, Iu.I. Bolotin, A.V. Sidliar. M.I. Rasskazov. Mining information-analytical bulletin. 4. 96-102. (2012).

5. M.I. Potapchuk, I.Iu. Rasskazov, G.M. Potapchuk, A.V. Sidliar. M. I. Rasskazov. Problems of complex exploration of geological resources: materials of the Fourth AllRussian scientific conference with foreign participants (Khabarovsk, September 27-29, 2011). In 2 vol. - Khabarovsk city, "Institute of Mining" of the FED RAS. 1. 110-117. (2011)

6. I.Iu. Rasskazov, B.G. Saksin, V.I. Usikov, M.I. Potapchuk. Mining Magazine. 12. 13-19 (2016)

7. B.F. Shevchenko, B.G. Saksin, M.I. Potapchuk. MIAB. S21. 182-191. (2016)

8. B.G. Saksin. I.Iu. Rasskazov // Problems of complex exploration of geological resources: materials of the Fourth All-Russian scientific conference with foreign participants (Khabarovsk, September 27-29, 2011). - Khabarovsk: "Institute of Mining" of the FED RAS. 1. 125-130. (2011)

9. L.I. Sosnovskii. L.I. Sosnovskii // Proceedings of Irkutsk State Technical University. 4. 32-33. (2006)

10. K.G. Levi. Irkutsk: IEC SB RAS. (2007) 